Philipp Bäumer, MD

Henrich Kele, MD

Annie Xia, BSc

Markus Weiler, MD

Daniel Schwarz, MD

Martin Bendszus, MD

Mirko Pham, MD

Correspondence to

Dr. Bäumer:

p.baeumer@dkfz-heidelberg.de

\section{Posterior interosseous neuropathy}

\section{Supinator syndrome vs fascicular radial neuropathy OPEN}

\section{ABSTRACT}

Objective: To investigate the spatial pattern of lesion dispersion in posterior interosseous neuropathy syndrome (PINS) by high-resolution magnetic resonance neurography.

Methods: This prospective study was approved by the local ethics committee and written informed consent was obtained from all patients. In 19 patients with PINS and 20 healthy controls, a standardized magnetic resonance neurography protocol at 3-tesla was performed with coverage of the upper arm and elbow (T2-weighted fat-saturated: echo time/repetition time $52 / 7,020$ milliseconds, in-plane resolution $0.27 \times 0.27 \mathrm{~mm}^{2}$ ). Lesion classification of the radial nerve trunk and its deep branch (which becomes the posterior interosseous nerve) was performed by visual rating and additional quantitative analysis of normalized T2 signal of radial nerve voxels.

Results: Of 19 patients with PINS, only 3 (16\%) had a focal neuropathy at the entry of the radial nerve deep branch into the supinator muscle at elbow/forearm level. The other 16 (84\%) had proximal radial nerve lesions at the upper arm level with a predominant lesion focus $8.3 \pm 4.6$ $\mathrm{cm}$ proximal to the humeroradial joint. Most of these lesions (75\%) followed a specific somatotopic pattern, involving only those fascicles that would form the posterior interosseous nerve more distally.

Conclusions: PINS is not necessarily caused by focal compression at the supinator muscle but is instead frequently a consequence of partial fascicular lesions of the radial nerve trunk the upper arm level. Neuroimaging should be considered as a complementary diagnostic method in PINS. Neurology ${ }^{\circledR}$ 2016;87:1884-1891

\section{GLOSSARY}

CSA = cross-sectional area; $\mathbf{M R N}=$ magnetic resonance neurography; $\mathbf{P I N}=$ posterior interosseous nerve; $\mathbf{P I N S}=$ posterior interosseous neuropathy syndrome; $\mathbf{R N}=$ radial nerve; $\mathbf{R O I}=$ region of interest.

The radial nerve $(\mathrm{RN})$ divides proximal to the elbow into a cutaneous sensory branch and a deep motor branch that pierces the supinator muscle at elbow level and then becomes the posterior interosseous nerve (PIN). Lesions of the $\mathrm{RN}$ or its motor branch can occur at any point along their course attributable to different causes such as trauma, tumor, compression, or inflammation. ${ }^{1}$ The clinical manifestation of a PIN lesion includes ulnar wrist drop and finger drop. More proximal lesions of the RN may include weakness of elbow extension, complete wrist drop, and supination weakness, depending on the precise localization of the lesion and the fascicles involved. One frequently considered cause of a PIN lesion has been nerve compression at the supinator muscle, referred to as supinator or PIN syndrome (PINS). ${ }^{2,3}$

Clinical and neurophysiologic criteria establish a diagnosis of PINS by the pattern of muscle involvement. ${ }^{1,4}$ This bears one significant pitfall: partial proximal nerve lesions may mimic and be potentially misdiagnosed as more distal lesions. ${ }^{1,5-7}$ Neuroimaging methods of nerve sonography and magnetic resonance neurography (MRN) directly visualize nerve lesions. ${ }^{8,9}$

From the Departments of Neuroradiology (P.B., A.X., D.S., M.B., M.P.) and Neurology (M.W.), Heidelberg University Hospital; Department of Radiology (P.B.), German Cancer Research Center, Heidelberg; and Center for Peripheral Neurology (H.K.), Hamburg, Germany; and the Department of Neuroradiology, University Clinic Würzburg.

Go to Neurology.org for full disclosures. Funding information and disclosures deemed relevant by the authors, if any, are provided at the end of the article. The Article Processing Charge was paid by Else Kröner-Fresenius-Stiftung.

This is an open access article distributed under the terms of the Creative Commons Attribution-NonCommercial-NoDerivatives License 4.0 (CC BY-NC-ND), which permits downloading and sharing the work provided it is properly cited. The work cannot be changed in any way or used commercially. 
Sonography in supinator syndrome has been reported to detect focal PIN swelling at entry into the supinator muscle. ${ }^{10-14} \mathrm{MRN}$ detects nerve lesions as increased T2-weighted signal and helps to discriminate neuropathies of compressive origin from other etiologies by the pattern of lesion localization. ${ }^{15,16}$ In this prospective investigation, we sought to determine lesion sites and the spatial pattern of lesion dispersion by MRN in patients with a clinical diagnosis of PINS.

METHODS Standard protocol approvals, registrations, and patient consents. The study was approved by the institutional ethics committee (S-398/2012). All participants gave written informed consent.

Clinical and demographic patient data. Patients included in the study were referred to our department with a clinical diagnosis of PINS due to muscle weakness and abnormal EMG results in the distribution of the PIN (i.e., extensor digitorum, extensor digiti minimi, extensor carpi ulnaris, abductor pollicis longus, extensor pollicis brevis, extensor pollicis longus, extensor indicis).

Patients with motor weakness involving more proximal muscles (triceps brachii muscle, brachioradialis, extensor carpi radialis longus and brevis) or EMG evidence of denervation in these were excluded from the study. Patients with sensory deficits, especially in the distribution of the superficial sensory $\mathrm{RN}$, were also excluded from the study. Furthermore, patients with nerve root compression (C6-C8) on cervical spine imaging were excluded from the study.

Overall, 28 patients ( 13 women, 15 men, mean age $48.5 \pm$ 15.5 years) fulfilled the inclusion criteria and were examined at the Department of Neuroradiology of Heidelberg University Hospital, Germany, between January 2010 and December 2015. Of these 28 patients, 9 were excluded after careful review of their history and after electrophysiologic reports revealed findings indicative of a neuropathy other than a compression neuropathy at the level of the supinator muscle ( 4 with additional sensory RN symptoms, 4 with more proximal muscle paresis or EMG evidence of denervation, one with cervical root compression at $\mathrm{C} 7$ ).

Twenty age- and sex-matched participants (8 women, 12 men, $49.9 \pm 16.7$ years) without symptoms or signs of radial neuropathy, or risk factors for polyneuropathy such as diabetes, chemotherapy, or infectious diseases, served as control group.

MRN imaging. Examinations were conducted using a 3-tesla unit (MAGNETOM Verio; Siemens AG, Erlangen, Germany) as described previously. ${ }^{16}$ Participants were examined in prone position in a knee 8-channel, phased-array receive coil with the arm in elbow extension. The magic angle effect was avoided by aligning the longitudinal axis of the upper arm at an angle of $\leq 10^{\circ}$ relative to the $\mathrm{B}_{0}$ field. Two to 3 image slabs were acquired for large imaging coverage of the RN, its branches, and the muscles it innervates in the forearm: (1) proximal: at the upper arm level; (2) central: at the elbow centered on the supinator muscle; and (in case forearm muscles were not sufficiently covered by sequence 2) by (3) at the forearm.

Sequence measures for the transversal T2-weighted turbo spin echo were as described previously ${ }^{16}$ : repetition time/echo time 6,980/52 milliseconds, spectral fat saturation, slice thickness
$3.0 \mathrm{~mm}$, number of slices 45 , interslice gap $0.3 \mathrm{~mm}$, field of view $130 \times 130 \mathrm{~mm}^{2}$, acquisition matrix $512 \times 358$, pixel spacing $0.254 \times 0.254 \mathrm{~mm}^{2}$, number of excitations $=3$, acquisition time 7:17 minutes.

As an option, an additional sagittal-oblique T2-weighted sequence using a dedicated surface coil (NORAS, Würzburg, Germany) was acquired for assessment of the brachial plexus with the following measures: repetition time/echo time 5,530/45 milliseconds, spectral fat saturation, slice thickness $3.0 \mathrm{~mm}$, number of slices 51, interslice gap $0.3 \mathrm{~mm}$, field of view $150 \times 150 \mathrm{~mm}^{2}$, acquisition matrix $320 \times 198$, pixel spacing $0.47 \times 0.47 \mathrm{~mm}^{2}$, number of excitations $=3$, acquisition time $7: 46$ minutes.

Qualitative image analysis. Images were assessed by 2 neuroradiologists (P.B., M.P.) with more than 7 and 10 years of experience in MRN, respectively, similar to a previous analysis ${ }^{17}$ regarding the following items:

1. Lesion determination: dichotomous consensus ratings regarding the presence or absence of lesions, based on T2-weighted signal increase and caliber of RN and PIN fascicles.

2. Predominant lesion localization: the anatomical position of predominant lesion focus of the PIN or RN, defined as strongest increase in T2-weighted signal and caliber, measured as distance from the humeroradial joint.

3. Fascicular involvement: dichotomous consensus ratings on lesion involvement of the entire nerve cross-section or only a partial cross-sectional area (CSA) (fascicular lesion).

4. Longitudinal involvement: those patients in whom an additional sequence of the brachial plexus was acquired were assessed for the presence of lesions within the brachial plexus cords.

Quantitative image and statistical analysis. Further steps on quantitative analysis were performed on a Siemens Syngo Workstation (SyngoMMWP VE31A, syngVE32B) by 2 investigators (P.B., A.X.) blinded to all participant data. Spatial registration for each participant was performed with reference to the humeroradial joint space. RN T2-weighted contrast was obtained at the site of predominant lesion focus by manual segmentation of the nerve circumference for measurement of signal intensities within this region of interest (nROI) as well as the CSA. For healthy controls, 2 positions were chosen: one $8.3 \mathrm{~cm}$ proximal to the humeroradial joint was chosen for this, corresponding to the mean distance of predominant proximal lesion focus in patients with proximal lesions; and another, $1.3 \mathrm{~cm}$ distal to the humeroradial joint, corresponding to the nerve entry to the supinator muscle. Additional ROIs were placed on the same slice within the long head of the biceps brachii muscle (mROI). For each participant, normalized RN T2 values were calculated as follows: $\mathrm{nT} 2=\mathrm{nROI} / \mathrm{mROI}$. Patient and control values were tested against each other using the 2 -sided Student $t$ test, with the significance level defined at $p<0.05$.

RESULTS Clinical findings and patient data. Nineteen patients ( 9 women, 10 men, mean age $48.5 \pm 14.7$ years) were included in the study with a diagnosis of PINS based on clinical examination and electrophysiologic test results (table).

Eight patients reported having initially experienced transient pain in the upper extremity, without evidence of sensory findings on physical examinations. Six patients had previously undergone operation for a presumed PIN compression syndrome at 


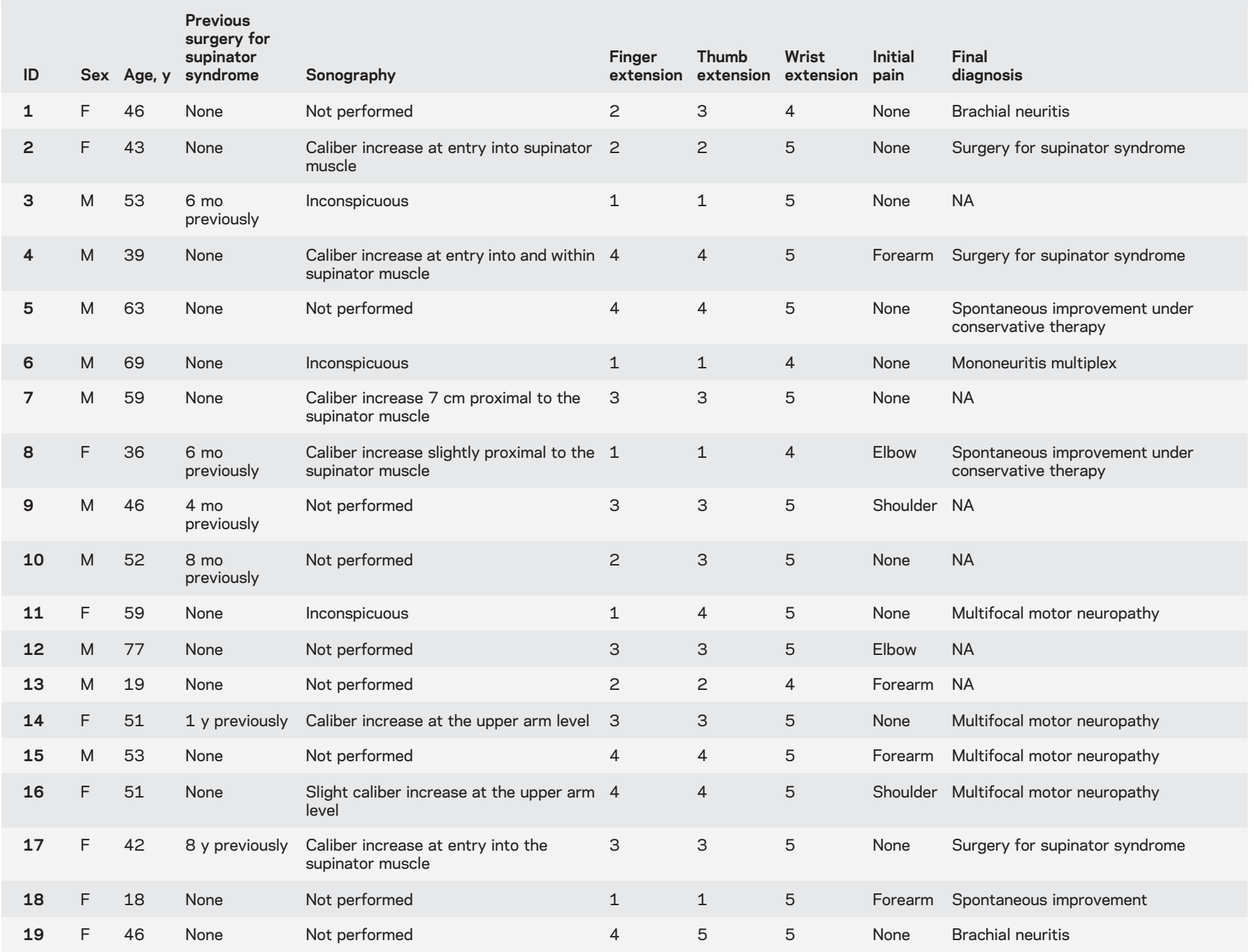

Muscle strength is given according to the grading (0-5) by the Medical Research Council. By definition of the inclusion criteria, muscle strength was 5 for all muscle groups not shown in the table.

the elbow but had not shown improvement in muscle strength. Sonography had been performed in $10 \mathrm{pa}-$ tients before MRN. In 4, sonographic findings with swelling at the entry into the supinator muscle appeared consistent with a compression neuropathy. In 2, unclear swelling of the $\mathrm{RN}$ was found at the upper arm level; in another one, nerve caliber was normal but slight hypoechogenicity of some fascicles was noted at the upper arm level. Three had normal ultrasound findings.

MRN imaging findings. None of the healthy controls displayed an increased T2-weighted signal in the RN. In contrast, all of the 19 patients with PINS exhibited abnormal findings on MRN: 3 (15.8\%) were found to have a focal neuropathy at the entry to or within the supinator muscle. Patients 2 and 17 were found to have increased signal at the exact point of entry into the supinator muscle. Patient 4 had severe swelling of the nerve within the supinator muscle. Unexpectedly, the other 16 patients (84.2\%) showed a distinct pattern with proximally located lesions within the RN (figure 1). All of these were apparent over a larger longitudinal segment of the RN trunk at the upper arm level.

Lesion localization. The distance of the predominant lesion focus within the PIN or RN was determined in relation to the elbow. For the 16 patients with proximally extending lesions, this was $8.3 \pm 4.6 \mathrm{~cm}$ proximal to the humeroradial joint, while for the 3 patients with focal nerve lesions within the supinator muscle, this was $1.3 \pm 1.8 \mathrm{~cm}$ distal to the humeroradial joint (equivalent to entry to or within the supinator muscle).

Of the 16 patients with a proximal lesion focus, pathologically increased T2-weighted signal was observed in the entire $\mathrm{RN}$ cross-section in 4 (25.0\%) of them, and no normal-appearing fascicles could reliably be distinguished at the level of 


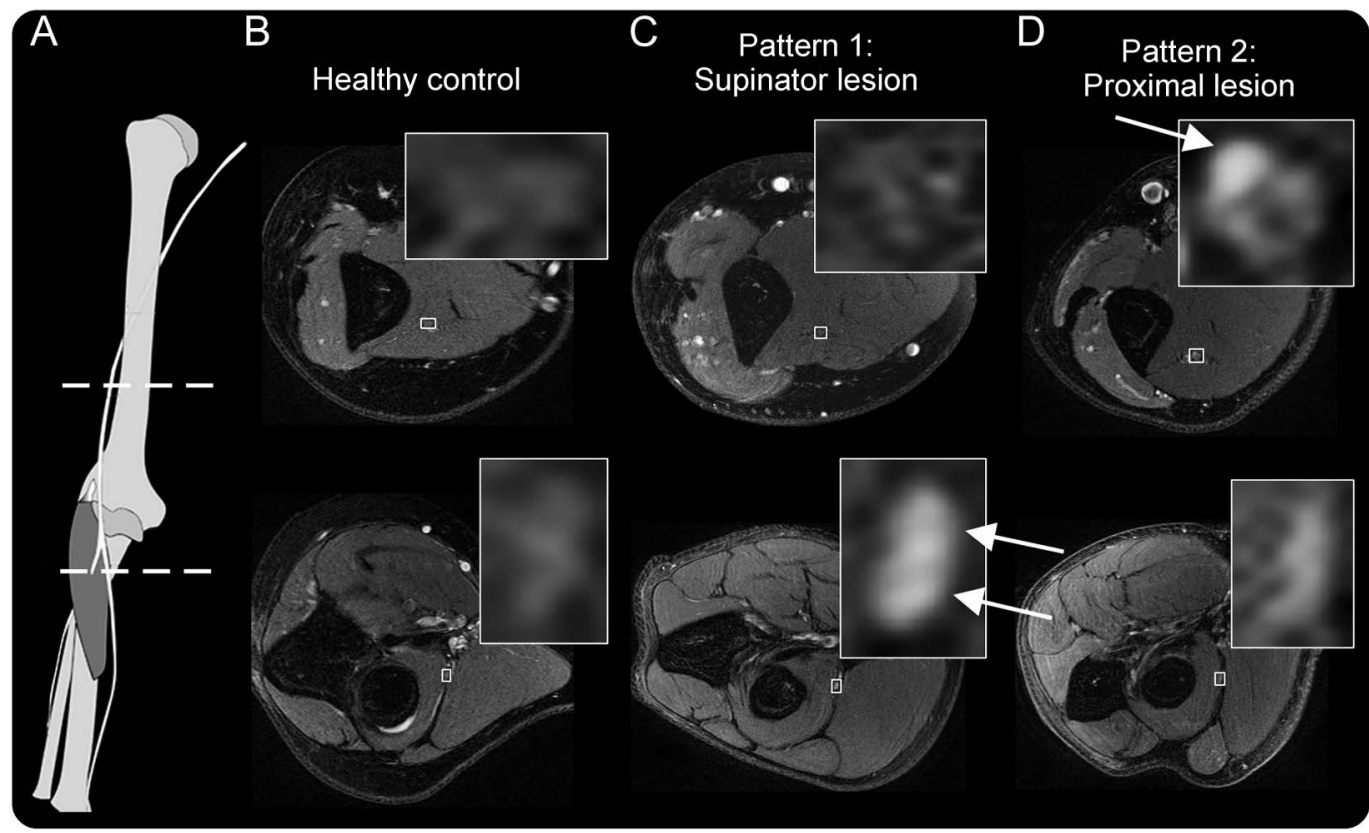

(A) Anatomical scheme of the radial nerve with dashed lines indicating the level of images. (B) Magnetic resonance neurography findings of a healthy control with normal radial nerve T2-weighted signal. (C, D) The first, expected pattern of findings for a patient presenting with posterior interosseous neuropathy syndrome: proximally at the upper arm level, a normal appearance and signal of the radial nerve, while after bifurcation and at entry into the supinator muscle, the nerve shows severely increased T2-weighted signal of the deep branch (arrow), in this case with little caliber increase. (D) A patient with the second lesion pattern: a proximal fascicular lesion, involving only a portion of the radial nerve trunk at the upper arm level (arrows).

predominant nerve lesion focus. The other 12 of 16 patients $(75.0 \%)$ had partial, fascicular lesions (figure 2). The precise location for these was in all cases at the dorsomedial portion of the $\mathrm{RN}$ cross-section, even when lesions extended proximally to the humeral groove. This lesion area coincided with the topographic internal arrangement of motor fascicles within the $\mathrm{RN}$, as originally depicted in a somatotopic map by Sunderland (figure 3). These hyperintense fascicles then continued distally to form the deep branch of the RN, or PIN. In contrast, the anterolateral fascicles were not involved and continued distally to form the superficial branch of the RN.

Lesion extension into the brachial plexus. In 8 of the 16 patients with proximal lesions, the longitudinal lesion extension at the upper arm level led to the acquisition of additional, optional imaging sequences to cover the brachial plexus in the same imaging session. Brachial plexus lesions were detected in 7 patients $(87.5 \%)$, all of them restricted to the posterior cord from which the $\mathrm{RN}$ arises. At the same time, no lesions were detected in the medial or lateral cord (figure 4).

Quantitative analysis. At the site of predominant lesion focus, mean normalized RN T2 signal was increased in patients with proximal lesions $(1.84 \pm 0.49$ vs $1.11 \pm 0.22 ; p<0.001)$. Likewise, CSA was increased in patients with proximal lesions compared to controls $\left(11.4 \pm 6.2\right.$ vs $6.7 \pm 1.3 \mathrm{~mm}^{2}$; $p<0.001)$. The 3 patients with PIN lesions in the supinator muscle had increased CSA $(10.7 \pm 12.9$ vs $\left.3.6 \pm 1.4 \mathrm{~mm}^{2} ; p=0.02\right)$ and T2 SR $(1.36+$ 0.07 vs $1.11+0.24 ; p=0.03)$ compared to controls at their site of predominant lesion focus in the supinator muscle.

DISCUSSION Patients with isolated finger drop are often primarily assumed to have a focal entrapment neuropathy caused by compression of the deep motor branch of the $\mathrm{RN}$ at the supinator tunnel. In this study, we present evidence by neuroimaging that initially unsuspected proximal lesions of the $\mathrm{RN}$ trunk at the upper arm level are frequently the cause of this clinical presentation.

The majority of our patients had proximal, longitudinally extending lesions along the upper arm, often selectively involving only dorsomedially located motor fascicles within the RN. In the literature, a number of scattered case reports exist that describe patients with a clinical picture initially consistent with PINS, who upon surgical exploration, had lesions in the RN or PIN at mostly proximal sites without detectable external compression. ${ }^{18-21}$ A single case report with confirmation by MRN findings was 


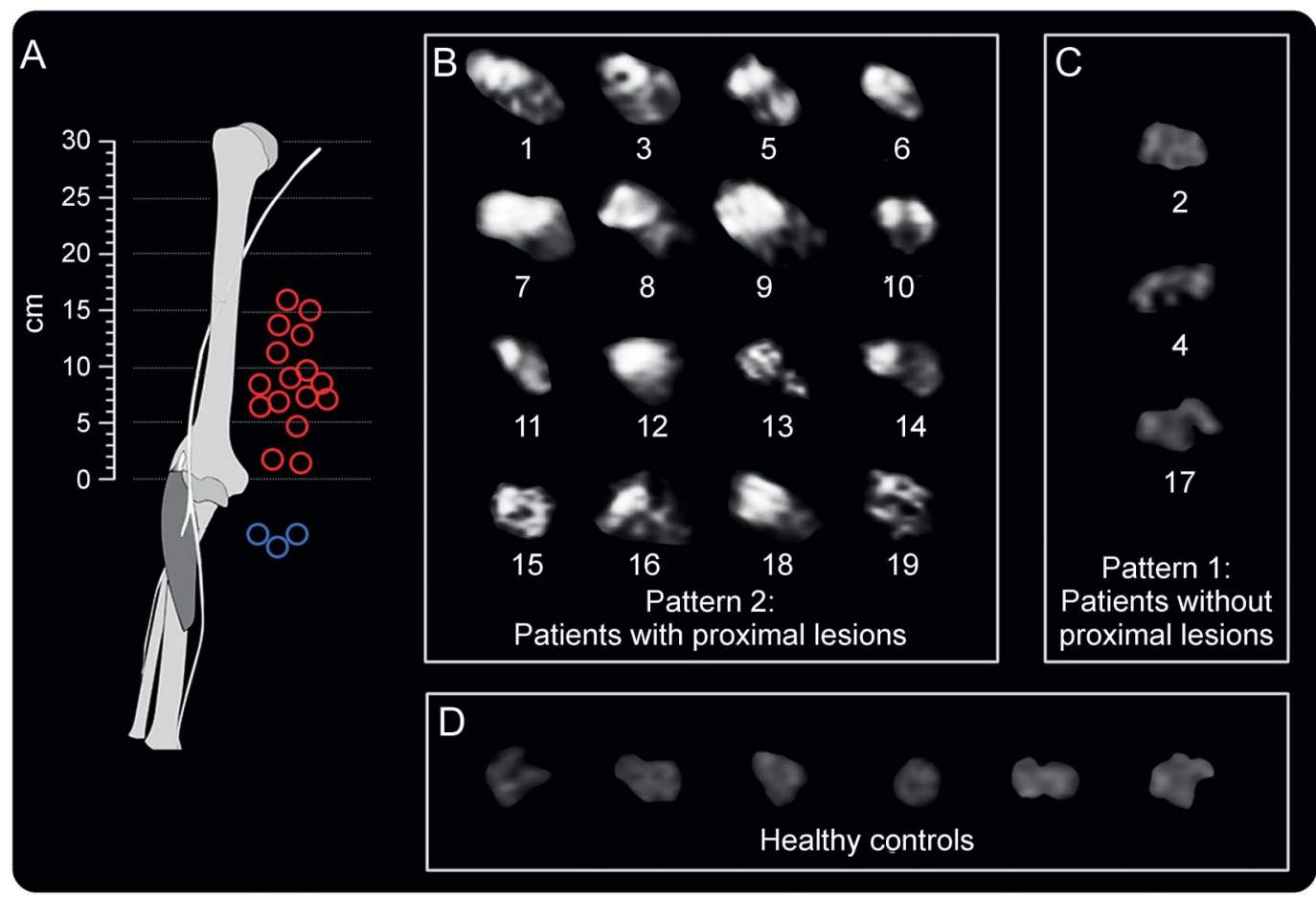

(A) Spatial of predominant individual lesion sites distributions (blue circles for pattern 1, red circles for pattern 2). (B) Array of individual radial nerve cross-sectional MRN images for the patient group with proximal lesions (pattern $2, n=16$, numbered in accordance with the table). (C) Proximal MRN cross-sections for patients with only distal lesions (pattern 1, $n=3$ ). Localization of individual lesion sites is given as distance in centimeters from the humeroradial joint space (at $0 \mathrm{~cm})$. Differences in individual arm lengths are not corrected for. In 12 of 16 patients with proximal lesions, strongly increased T2 signal (bright) was found not in the entire cross-section but only within a group of fascicles whereas other fascicles were spared. (D) Nerve T2 signal was normal in controls (showing 6 representatives of 20 controls).

recently added to these few individual descriptions. ${ }^{22}$ Our study is the first to systematically investigate this observation in a larger group of patients with PINS.

How can we account for this apparent discrepancy between clinical reasoning and neuroimaging results? There are 2 potential explanations.

The first explanation is based on the concept of peripheral nerve somatotopy. Peripheral nerves are now known to harbor a high degree of consistent longitudinal arrangement of their fascicles ${ }^{23-25}$ with highly relevant clinical implications for lesion localization in the PNS. If a given proximal nerve lesion involves specifically only those fascicles destined to form a particular branch that leaves the nerve more distally, but does not involve fascicles to other branches, the clinical manifestation of this lesion will mimic a more distal lesion of the particular branch.? This is obvious in the case of traumatic partial nerve injuries. ${ }^{26,27}$ In spontaneously occurring neuropathies, it represents a major pitfall in diagnosis, ${ }^{6,28}$ as has recently been shown for the anterior interosseous nerve syndrome. ${ }^{17}$ Historical dissections of the RN and its branches suggest that the $\mathrm{RN}$ is also potentially susceptible to such erroneous localization of a lesion. ${ }^{29}$ The observed somatotopic lesion pattern in our patients, in close correspondence to the somatotopic mappings obtained from Sunderland ex vivo, seems to confirm this hypothesis.

The other potential explanation would be a length-dependence of the underlying disease. A length-dependent occurrence of symptoms has been investigated for many polyneuropathies including diabetic polyneuropathy, immunoglobulin $M$ gammopathy-associated polyneuropathy, or multifocal motor neuropathy. ${ }^{30-32}$ Recent neuroimaging studies of diabetic and neurofibromatosis-associated polyneuropathies have shown the disseminated multifocality of nerve lesions whose cumulation correlates with symptom severity. ${ }^{33,34}$ A length-dependent radial mononeuropathy could first present with finger drop, as seen in our patients, before eventually proceeding to involve additional muscles. This was actually the case in 4 patients excluded from our study because their disease had progressed before the MRI to also involve more proximal muscles. Lengthdependence therefore seems to be an additional possible explanation.

The longitudinal and disseminated involvement of the RN suggests an inflammatory process as underlying disease entity. ${ }^{16,17}$ Clinical follow-up was not part 


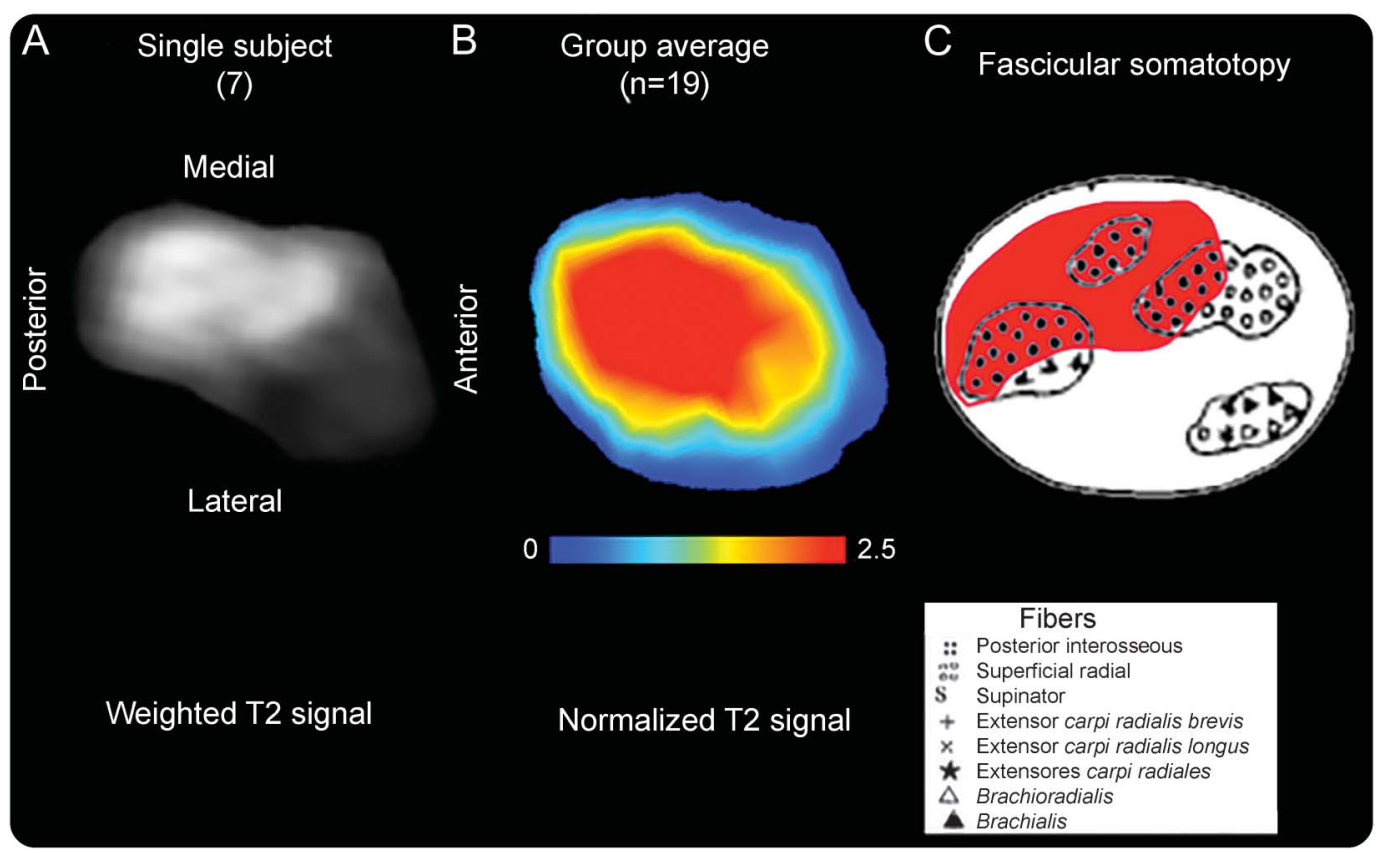

(A) The T2-weighted source image of the radial nerve of patient 7 is shown for the site of predominant lesion focus $(9.6 \mathrm{~cm}$ proximal to the humeroradial joint). Anatomical orientation is given by labeling ventral/dorsal/medial/lateral contours. (B) Spatial map of the patient group mean normalized T2 signal. This cross-sectional lesion area is at the dorsal/posterior and medial aspect of the radial nerve at the upper arm level with a mean distance of $8.3 \mathrm{~cm}$ proximal to the humeroradial joint space. The map was rendered after segmentation and intersubject image registration. (C) Somatotopic/topographic internal map of fascicles of the radial nerve trunk, obtained ex vivo as schematic drawing (modified from Sunderland S. The intraneural topography of the radial, median and ulnar nerves. Brain 1945;68:243-299,29 by permission of Oxford University Press). On this map, the fascicles identified as posterior interosseous fascicles (black filled dots with red background) are in spatial arrangement with the T2 lesion focus on individual (A) and group level (B). Note that lesion focus appears larger on the averaged map compared to historical map partly because of swelling of involved fascicles present in patients but not in specimens used by Sunderland.

of the study design, but several patients were subsequently diagnosed with an inflammatory nerve condition such as multifocal motor neuropathy. The documented extension of lesions into the posterior cord of the brachial plexus in several patients also points to an overlap with brachial plexus neuritis. In fact, certain patients with Parsonage-Turner syndrome are known to present with symptoms pointing toward involvement along the peripheral nerve trunks distal to the level of the brachial plexus. Furthermore, the transient pain at symptom onset that several patients reported is a typical infrequent feature of inflammatory nerve conditions such as multifocal motor neuropathy or neuralgic amyotrophy. . $^{35,36}$

The clinical implication of our study, then, is that neuroimaging including the proximal course of the $\mathrm{RN}$ should be considered for patients presenting with finger drop since clinical reasoning alone and EMG cannot always reliably differentiate between sole compression at the elbow and selective fascicular involvement of proximal nerve portions at the upper arm level. This is especially relevant for patients who would otherwise undergo surgical exploration for presumed compression of the nerve at the elbow.
Imaging will either allow for more precise planning of the surgical strategy if focal, compressive structures can be identified, or it may render surgery altogether inappropriate. A second interesting implication of the study is the clinical relevance of peripheral nerve somatotopy, which can be delineated by $\mathrm{MRN}^{7,17,25}$ and which was in good agreement with historical dissection findings by Sunderland. ${ }^{29}$

Ultrasound was not part of the standard protocol in our study. In 3 of the 10 patients who underwent ultrasound examination before MRI, proximal RN abnormalities were also documented on nerve ultrasound. Nerve caliber increase at proximal arm positions can well be detected by ultrasound experts and has been described in the literature to detect RN lesions. ${ }^{37-39}$ Caliber-neutral lesions are much harder to identify, and MRN likely has better sensitivity for these lesions. ${ }^{17}$ Generally, ultrasound seems feasible for detection of distal nerve lesions while MRN is likely necessary for far proximal lesions. ${ }^{39}$

There are limitations to our study. Our patient population should not be considered fully representative for all patients presenting with finger drop since 6 patients had already been operated without 


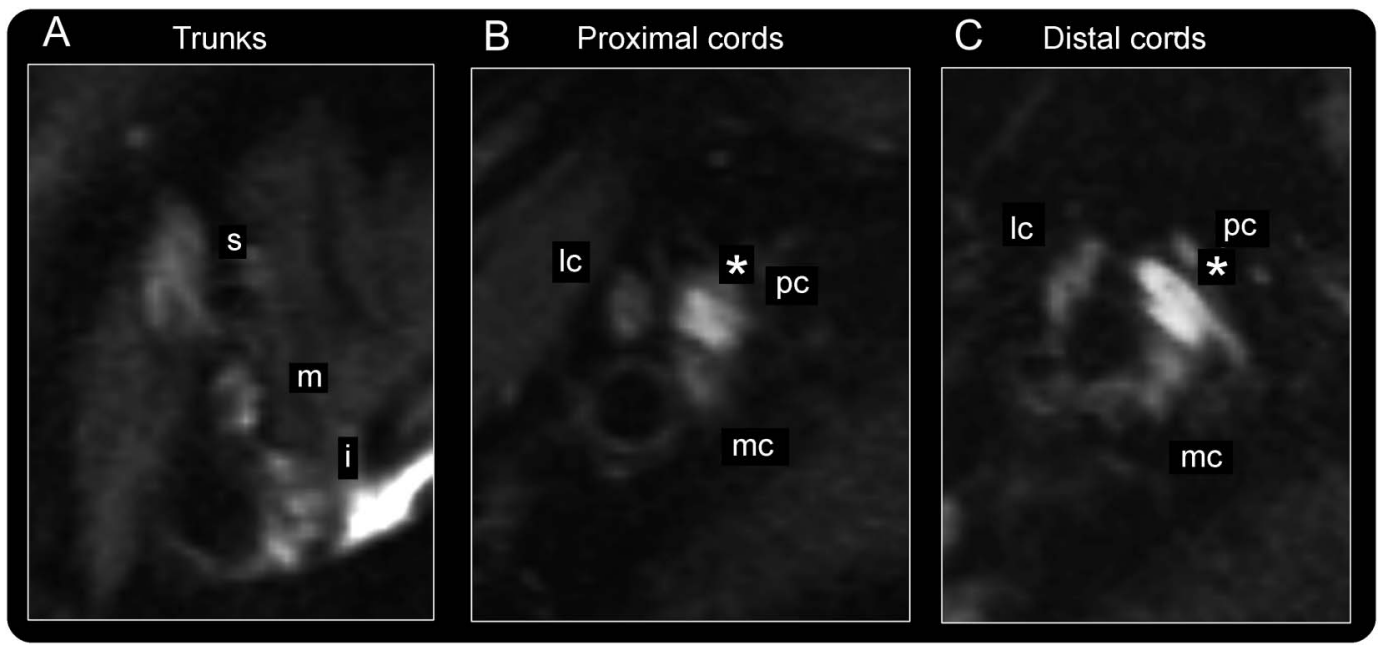

Representative brachial plexus imaging findings for patient 19 are displayed. (A) At trunk level, superior (s), medial (m), and inferior (i) trunk appear normal, without increased T2 signal. (B, C) At cord levels, the posterior cord (pc; from which the radial nerve arises more distally) is severely thickened and shows high T2 signal (marked by *) as typical imaging findings of selective plexopathy. The lesion extends continuously through the posterior cord into the radial nerve. Lateral (Ic) and medial cord (mc) are inconspicuous.

subsequent improvement, and 3 had abnormal ultrasound examinations at the upper arm. The percentage of true supinator syndrome as a compression neuropathy in patients presenting with finger drop is therefore likely higher than the $16 \%$ we observed. Another limitation is that patients with this rare condition were referred from different centers so that clinical examination before the MRI could not be fully standardized.

The study shows that selective proximal $\mathrm{RN}$ lesions can account for the clinical appearance of PINS. These lesions can be detected by neuroimaging for accurate lesion localization to complement the basis for correct clinical diagnosis and therapy.

\section{AUTHOR CONTRIBUTIONS}

Philipp Bäumer: study design, acquisition of data, analysis and interpretation of data, writing of manuscript. Henrich Kele: study design, acquisition of data, analysis and interpretation of data, revising manuscript for intellectual content. Annie Xia: acquisition of data, revising manuscript for intellectual content. Markus Weiler: acquisition of data, analysis and interpretation of data, revising manuscript for intellectual content. Daniel Schwarz: acquisition of data, revising manuscript for intellectual content. Martin Bendszus: study supervision, revising manuscript for intellectual content. Mirko Pham: study design, analysis and interpretation of data, revising manuscript for intellectual content.

\section{STUDY FUNDING}

This study was supported by a postdoctoral fellowship granted to P.B. from the Medical Faculty of the University of Heidelberg and by a memorial stipend to M.P. from the Else Kröner-Fresenius-Stiftung.

\section{DISCLOSURE}

P. Bäumer reports a postdoctoral fellowship from the Medical Faculty of the University of Heidelberg. H. Kele, A. Xia, M. Weiler, and D. Schwarz report no disclosures relevant to the manuscript. M. Bendszus reports personal fees from Codman, grant from the Deutsche
Forschungsgemeinschaft, grants and personal fees from Novartis, personal fees from Vascular Dynamics, grants and personal fees from Guerbet, personal fees from Roche, grants from Hopp Foundation, grants from Siemens, personal fees from Teva, grants from Stryker, grants from Covidien, all outside the submitted work. M. Pham reports a memorial stipend from Else Kröner-Fresenius-Stiftung and a project grant from the Deutsche Forschungsgemeinschaft. Go to Neurology. org for full disclosures.

Received April 11, 2016. Accepted in final form July 12, 2016.

\section{REFERENCES}

1. Wilbourn AJ, Ferrante MA. Upper limb neuropathies: long thoracic, suprascapular, axillary, musculocutaneous, radial, ulnar, and medial antebrachial cutaneous. In: Dyck PJ, Thomas PK, editors. Peripheral Neuropathy, 4th ed. Philadelphia: Elsevier Saunders; 2005:1478-1483.

2. Spinner RJ, Amadio PC. Compressive neuropathies of the upper extremity. Clin Plast Surg 2003;30:155-173, vi.

3. Dawson DM, Hallett M, Wilbourn AJ. Radial nerve entrapment. In: Dawson DM, Hallett M, Wilbourn AJ, editors. Entrapment Neuropathies. Philadelphia: Lippincott-Raven; 1999:198.

4. Kim SJ, Hong SH, Jun WS, et al. MR imaging mapping of skeletal muscle denervation in entrapment and compressive neuropathies. Radiographics 2011;31:319-332.

5. Bevelaqua AC, Hayter CL, Feinberg JH, Rodeo SA. Posterior interosseous neuropathy: electrodiagnostic evaluation. HSS J 2012;8:184-189.

6. Trojaborg W. Rate of recovery in motor and sensory fibres of the radial nerve: clinical and electrophysiological aspects. J Neurol Neurosurg Psychiatry 1970;33:625-638.

7. Stewart JD. Peripheral nerve fascicles: anatomy and clinical relevance. Muscle Nerve 2003;28:525-541.

8. Martinoli C. Imaging of the peripheral nerves. Semin Musculoskelet Radiol 2010;14:461-462.

9. Beekman R, Visser LH. High-resolution sonography of the peripheral nervous system: a review of the literature. Eur J Neurol 2004;11:305-314. 
10. Bodner G, Harpf C, Meirer R, Gardetto A, Kovacs P, Gruber H. Ultrasonographic appearance of supinator syndrome. J Ultrasound Med 2002;21:1289-1293.

11. Joy V, Therimadasamy A, Cheun CY, Wilder-Smith E. Diagnostic utility of ultrasound in posterior interosseous nerve syndrome. Arch Neurol 2009;66:902-903.

12. Djurdjevic T, Loizides A, Loscher W, Gruber H, Plaikner M, Peer S. High resolution ultrasound in posterior interosseous nerve syndrome. Muscle Nerve 2014;49:35-39.

13. Lammer AB, Schwab S, Schramm A. Ultrasound in dual nerve impairment after proximal radial nerve lesion. PLoS One 2015;10:e0127456.

14. Wininger YD, Buckalew NA, Kaufmann RA, Munin MC. Ultrasound combined with electrodiagnosis improves lesion localization and outcome in posterior interosseous neuropathy. Muscle Nerve 2015;52:1117-1121.

15. Baumer P, Dombert T, Staub F, et al. Ulnar neuropathy at the elbow: MR neurography—nerve T2 signal increase and caliber. Radiology 2011;260:199-206.

16. Baumer $P$, Weiler M, Ruetters $M$, et al. MR neurography in ulnar neuropathy as surrogate parameter for the presence of disseminated neuropathy. PLoS One 2012;7: e49742.

17. Pham M, Baumer P, Meinck HM, et al. Anterior interosseous nerve syndrome: fascicular motor lesions of median nerve trunk. Neurology 2014;82:598-606.

18. Umehara F, Yoshino S, Arimura Y, Fukuoka T, Arimura $\mathrm{K}$, Osame M. Posterior interosseous nerve syndrome with hourglass-like fascicular constriction of the nerve. J Neurol Sci 2003;215:111-113.

19. Burns J, Lister GD. Localized constrictive radial neuropathy in the absence of extrinsic compression: three cases. J Hand Surg Am 1984;9A:99-103.

20. Belsole RJ, Lister GD, Kleinert HE. Polyarteritis: a cause of nerve palsy in the extremity. J Hand Surg Am 1978;3: 320-325.

21. Fernandez E, Di Rienzo A, Marchese E, Massimi L, Lauretti L, Pallini R. Radial nerve palsy caused by spontaneously occurring nerve torsion: case report. J Neurosurg 2001;94:627-629.

22. Yang JS, Cho YJ, Kang SH, Choi EH. Neuralgic amyotrophy manifesting as mimicking posterior interosseous nerve palsy. J Korean Neurosurg Soc 2015;58:491-493.

23. Jabaley ME, Wallace WH, Heckler FR. Internal topography of major nerves of the forearm and hand: a current view. J Hand Surg Am 1980;5:1-18.

24. Chow JA, Van Beek AL, Meyer DL, Johnson MC. Surgical significance of the motor fascicular group of the ulnar nerve in the forearm. J Hand Surg Am 1985;10:867-872.
25. Baumer P, Weiler M, Bendszus M, Pham M. Somatotopic fascicular organization of the human sciatic nerve demonstrated by MR neurography. Neurology 2015;84: 1782-1787.

26. Marie P. Les localisations motrices dans les nerfs peripheriques. Bull Acad Med 1915:798-810.

27. Dejerine J, Dejerine A, Mouzon J. Les lésions des gros troncs nerveux des membres par projectiles de guerre. Presse Méd 1915;40:321-328.

28. Stewart JD. The variable clinical manifestations of ulnar neuropathies at the elbow. J Neurol Neurosurg Psychiatry 1987;50:252-258.

29. Sunderland S. The intraneural topography of the radial, median and ulnar nerves. Brain 1945;68:243-299.

30. Franssen H, Notermans NC. Length dependence in polyneuropathy associated with IgM gammopathy. Ann Neurol 2006;59:365-371.

31. Van Asseldonk JT, Van den Berg LH, Van den Berg-Vos RM, Wieneke GH, Wokke JH, Franssen H. Demyelination and axonal loss in multifocal motor neuropathy: distribution and relation to weakness. Brain 2003;126: 186-198.

32. Dyck PJ, Karnes JL, O'Brien P, Okazaki H, Lais A, Engelstad J. The spatial distribution of fiber loss in diabetic polyneuropathy suggests ischemia. Ann Neurol 1986;19: 440-449.

33. Baumer P, Mautner VF, Baumer T, et al. Accumulation of non-compressive fascicular lesions underlies NF2 polyneuropathy. J Neurol 2013;260:38-46.

34. Pham M, Oikonomou D, Hornung B, et al. MR neurography detects diabetic neuropathy early and with proximal predominance. Ann Neurol 2015;78:939-948.

35. Suarez GA. Immune brachial plexus neuropathy. In: Dyck PJ, Thomas PK, editors. Peripheral Neuropathy. Philadelphia: Elsevier Saunders; 2005:2299-2308.

36. van Alfen N, van Engelen BG. The clinical spectrum of neuralgic amyotrophy in 246 cases. Brain 2006;129: 438-450.

37. Rossey-Marec D, Simonet J, Beccari R, et al. Ultrasonographic appearance of idiopathic radial nerve constriction proximal to the elbow. J Ultrasound Med 2004;23:1003-1007.

38. Erra C, De Franco P, Granata G, et al. Secondary posterior interosseous nerve lesions associated with humeral fractures. Muscle Nerve 2016;53:375-378.

39. Dietz A, Bucelli R, Pestronk A, Zaidman C. Nerve ultrasound identifies abnormalities in the posterior interosseous nerve in patients with proximal radial neuropathies. Muscle Nerve 2015;52:S61. 


\section{Neurology}

Posterior interosseous neuropathy: Supinator syndrome vs fascicular radial neuropathy Philipp Bäumer, Henrich Kele, Annie Xia, et al.

Neurology 2016;87;1884-1891 Published Online before print September 28, 2016

DOI 10.1212/WNL.0000000000003287

This information is current as of September 28, 2016

\section{Updated Information \&} Services

References

Subspecialty Collections

Permissions \& Licensing

Reprints including high resolution figures, can be found at: http://n.neurology.org/content/87/18/1884.full

This article cites 35 articles, 6 of which you can access for free at: http://n.neurology.org/content/87/18/1884.full\#ref-list-1

This article, along with others on similar topics, appears in the following collection(s):

MRI

http://n.neurology.org/cgi/collection/mri

Peripheral neuropathy

http://n.neurology.org/cgi/collection/peripheral_neuropathy

Information about reproducing this article in parts (figures,tables) or in its entirety can be found online at:

http://www.neurology.org/about/about_the_journal\#permissions

Information about ordering reprints can be found online:

http://n.neurology.org/subscribers/advertise

Neurology ${ }^{\circledR}$ is the official journal of the American Academy of Neurology. Published continuously since 1951, it is now a weekly with 48 issues per year. Copyright () 2016 American Academy of Neurology. All rights reserved. Print ISSN: 0028-3878. Online ISSN: 1526-632X.

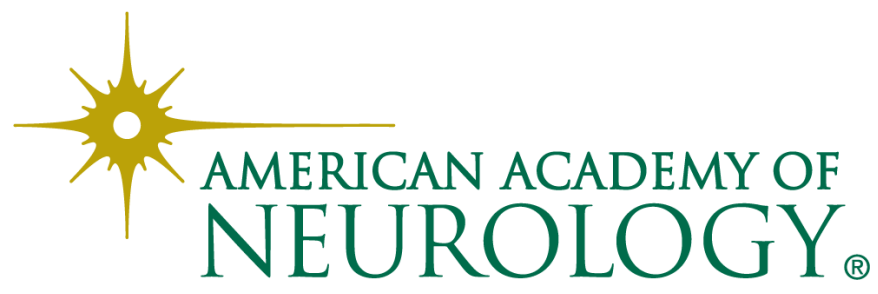

